\title{
La nación-república en el Discurso de Angostura de Simón Bolívar*
}

DOI: 10.17230/co-herencia.16.31.12

\author{
Liliana María López** \\ llopezlo@eafit.edu.co
}

Resumen El análisis propuesto en este texto señala que, en el proceso de imaginar y hacer posible la nación moderna en la América hispánica, el Libertador Simón Bolívar (1783-1830) invocó el origen cívico y revolucionario de los nacientes Estados, y no la uniformidad etnocultural. En este aspecto, su postura fue radicalmente moderna y antigenealógica, en tanto afirmó que la unidad del carácter que supone la nación como comunidad política no tiene que coincidir, necesariamente, con los límites de las nacionalidades. Este artículo toma como referencia el Discurso de Angostura, pronunciado por el Libertador en 1819, para mostrar que, al momento de construir esa gran nación que se debía llamar Colombia, Bolívar apeló a premisas políticas y territoriales, y no a los presupuestos nacionalistas de igualdad lingüística, racial o cultural. En tal sentido, su propuesta constitucional se inscribe en la tradición del patriotismo republicano y el ideal de la nación de ciudadanos.

\section{Palabras clave:}

Colombia, Discurso de Angostura, Simón Bolívar, nación cívica, republicanismo.

\section{The nation-republic in Discurso de Angostura by Simón Bolívar}

Abstract This paper argues that, in the process of imagining and making possible the modern nation in Spanish America, the Liberator Simón Bolívar (1783-1830) resorted to the civic and revolutionary origin of the nascent States, rather than to ethnocultural uniformity. In this regard, his position was radically modern and antigenealogical, in that he asserted that the character unity entailed by the nation as a political community does not need to match the limits of nationalities. This paper draws upon Discurso de Angostura, delivered by the Liberator in 1819 , to show that, at the time of building that great nation that should be called Colombia, Bolivar appealed to political and territorial premises, rather than to nationalist premises of linguistic, ethnic or cultural equality. In this regard, his constitutional proposal is in line with the tradition of republican patriotism and the ideal of the nation of citizens.

\section{Keywords:}

Colombia, Discurso de Angostura, Simón Bolívar, civic nation, republicanism.

Este texto hace parte de la investigación "Lugareños, patriotas y cosmopolitas: un estudio de los conceptos de patria y nación en el siglo xix colombiano", inscrita en el grupo de investigación Estudios en filosofía, hermenéutica y narrativa, del Departamento de Humanidades, Universidad EAFIT.

Doctora en Humanidades de la Universidad EAFIT, y magíster en Filosofía de la Universidad de Antioquia. Profesora titular de la Universidad EAFIT. 


\section{La singularidad del caso americano}

Las nuevas lecturas sobre las guerras de Independencia en Hispanoamérica indican que la identidad nacional en la América independiente fue un asunto muy complejo, poco evidente y tardío, pues, para la época, no existía la uniformidad etnocultural que se presupone como condición necesaria de unidad nacional, y tampoco los fundamentos normativos que convierten a una sociedad en verdadera república. Es decir, además de la homogeneidad cultural y étnica, faltaba la homogeneidad ética y política que supone una sociedad pacificada y dispuesta a formar, en su seno, un poder unitario que nadie considere hostil. El balance de Simón Bolívar fue claro al respecto. Para el Libertador, el pueblo americano estaba atado "al triple yugo de la ignorancia, de la tiranía y del vicio” y, además, era un pueblo heterogéneo, sin carácter nacional, de bajo nivel de instrucción y sin experiencia en el ejercicio de la libertad (Bolívar, 1819b).

Esas lecturas cuestionan la idea de que la Independencia estuvo fundada en un principio de nacionalidad que procedía de la Colonia, y aseveran que la mayoría de los elementos que constituyen lo que usualmente se define como "principio de nacionalidades", es decir, la identidad de origen, religión, lengua e historia, no solo eran comunes a toda la América hispánica, sino también a gran parte de la España peninsular. El gran reto de los patriotas criollos y libertadores hispanoamericanos fue, entonces, el de construir e imaginar un Estadonación separado a partir de una nacionalidad que era común a todos (Guerra, 2012, p. 229). En otras palabras, el problema específico de la América hispánica no era la presencia de pueblos homogéneos y perfectamente diferenciados constituyéndose en naciones.

A diferencia del ciclo nacionalizador europeo, que dotó a viejas estructuras culturales, lingüísticas y étnicas de un sentido nacional, la América hispánica -Colombia incluida- buscó romper, radicalmente, la continuidad histórica, política y cultural con la monarquía hispánica. Es justamente por esto que, en el proceso de construcción de las nuevas naciones hispanoamericanas, el principio de naciona-

1 El texto del Discurso de Angostura referenciado aquí se publicó, por entregas, en cuatro números del Correo del Orinoco, entre el 20 de febrero y el 13 de marzo de 1819. El periódico carece de numeración de páginas. 
lidad se usaba, básicamente, en un sentido político. Se trataba de delimitar el territorio y definir la soberanía, la ciudadanía y el régimen de gobierno, y no de establecer fronteras culturales, étnicas, lingüísticas o demarcar comunidades de gentes unidas en torno a una misma raza, lengua, costumbres o religión.

Que la nación fue una creación, y no el despertar de unas naciones americanas gestadas a lo largo del periodo colonial es una premisa aceptada no solo por los historiadores del presente, sino también por los publicistas e intelectuales a lo largo del siglo XIX. José María Samper (1828-1888), por ejemplo, señalaba que los próceres y libertadores se vieron en la difícil tarea de crearlo todo de la nada, sin maestros ni escuela y sin pasado nacional. En el texto Galería nacional de hombres ilustres o notables, Samper (1879) destaca la creación ex nihilo de la nación en Colombia, y señala que a esos "grandes hombres, inexpertos en todo", les tocó la tarea de obrar en un vasto territorio, desprovisto de recursos, ajeno y hostil. Para este liberal de fronteras imprecisas, antes de la Independencia, no había patria ni nación preexistente y no existía un pasado legítimo por rememorar o reactualizar. Por el contrario, existían muchas prácticas y costumbres por demoler. Los patriotas y libertadores tuvieron que afrontar, en ese sentido, la difícil tarea de crearlo todo, "empezando por hacerse ellos mismos republicanos y ciudadanos, no obstante, la secuestrada educación colonial que habían recibido" (Samper, 1879, p. 6).

La no existencia, en Colombia, durante el comienzo del siglo XIX, de un principio de nacionalidad con matiz etnocultural y una idea de unidad política con fronteras culturales preexistentes o derivada de una nación histórica, no significa que no existiera un principio de nacionalidad. Habría sido difícil concebir una idea territorial e institucional de la nación, que operara como síntesis de la búsqueda de la autodeterminación política, si las élites dirigentes no hubieran aprovechado el potencial revolucionario y constituyente desatado por la crisis de la península ibérica en el año de 1808 (Guerra, 1992, pp. 118-129; König, 1994, pp. 86-90). La idea que se quiere acentuar aquí es que, en Colombia, primero se construyó un proyecto de Estado y, solo después, una cultura nacional desprovista de ingredientes étnicos. ${ }^{2}$

2 Esto le otorga a la personalidad histórica de Colombia un carácter de mesura o medianía, 
El discurso pronunciado por Bolívar en Angostura, en 1819, resulta meridiano en ese sentido, pues se encuentra dirigido a naciones sin identidad étnica, sin cohesión cultural y sin experiencia en la ciencia de gobierno. Es decir, no estaba dirigido a naciones antiguas que se hubiesen liberado de un imperio, por obra de una autoconciencia nacional, sino a poblaciones heterogéneas y nacidas, precisamente, del desplome de ese imperio. Por tal razón, se puede afirmar que las patrias hispanoamericanas fueron creaciones que se apoyaron, exclusivamente, en valores políticos y sentimentales como el patriotismo, el estatus de ciudadanía, las virtudes cívicas, los recuerdos compartidos y el principio del uti possidetis. ${ }^{3}$

Estos asuntos ponen de relieve la ambigüedad inherente al proceso de invención de las nuevas naciones y patrias americanas. Aunque la identidad americana predicada desde finales del siglo XVIII pudiera cumplir una función importante al momento de trazar la distinción política con la España peninsular, ella resultaba insuficiente para fundar la existencia política y cultural de una nación moderna. Como lo ha mostrado José Carlos Chiaramonte (2008), para el caso del Virreinato del Río de la Plata, el sentimiento americano mantuvo su fuerza durante los primeros años de lucha por la independencia, porque expresaba el dato inmediato y reconocible de haber nacido en el Nuevo Mundo, pero no correspondía a ninguna identidad nacional específica. Para Chiaramonte (2008), resulta bastante paradójico que las élites patrióticas y libertadoras de la época se presentaran como americanos o como españoles-americanos, y nosotros las leamos como mexicanos, argentinos, peruanos o colombianos (p. 17).

El Discurso de Angostura resulta esclarecedor para entender esta especificidad del caso hispanoamericano. En él, Bolívar afirmó que después de desprenderse de la monarquía española, América se encontró en una situación semejante a la del Imperio Romano, cuando

debido a la ausencia de divisiones étnicas, tan fuertes en países como México, Perú y Bolivia (Jaramillo, 1994, p. 34).

3 El principio del uti possidetis juris fue utilizado para el deslinde territorial de las diferentes nacionalidades hispanoamericanas. Este principio prescribía que cada una de las naciones que, en 1810, transitaban de su condición de colonias a repúblicas, podían conservar los territorios y límites fronterizos que ostentaban cuando eran posesiones y unidades administrativas de la Corona española (Quijano, 1881, pp. 315-316). 
aquella enorme masa cayó dispersa en medio del Antiguo Mundo y cada desmembración formó una nación independiente. Sin embargo, para Bolívar, la América hispánica constituía un caso extraordinario y muy complicado. Mientras los miembros del Imperio Romano volvían a restablecer sus primeras asociaciones, nosotros -decía Bolívar-

ni aún conservamos los vestigios de lo que fue en otro tiempo: no somos europeos, no somos indios, sino una especie media entre los aborígenes y los españoles. Americanos por nacimiento y europeos por derechos, nos hallamos en el conflicto de disputar a los naturales los títulos de posesión y de mantenernos en el país que nos vio nacer, contra la oposición de los invasores (Bolívar, 1819b).

En este fragmento, Bolívar identifica la singularidad del caso hispanoamericano e insinúa la disociación existente entre la nación étnica y la política. Cuando alude a la idea de espíritu nacional hace referencia, en lo fundamental, a formas abstractas de integración social mediadas por la acción del Estado y sus instituciones legales. La unidad nacional se predica, solamente, como una inclinación orientada a tres puntos: moderar la voluntad general, limitar la autoridad y construir las instituciones para formar el carácter nacional y las costumbres del pueblo. Esta idea mínima y, si se quiere, liberalrepublicana de unidad nacional supone que la dimensión política e institucional de la nación se sobrepone a la dimensión cultural y étnica de la identidad nacional.

La radical dicotomía entre el ius soli-derecho de suelo- y el ius sanguinis -derecho de sangre- puede resultar históricamente inexacta y ser sociológicamente engañosa, sobre todo, para el caso de aquellas naciones nacidas de comunidades étnicas que se transforman, gradualmente, en comunidades políticas, basadas en un territorio. No obstante, para el caso de la Colombia decimonónica, esta distinción resulta muy ilustrativa, pues el fundamento de la nacionalidad no estaba apoyado ni en una comunidad histórica de continuidad serial ni se sustentaba en la afinidad o la descendencia biológica. En el vasto e inexplorado territorio de la nación colombiana, había "pueblos distintos", etnias diferenciadas con muy pocas cosas en común. Muchas sangres y mezclas de sangres, y una gran diversidad de culturas (Núñez, 1986, pp. 23-24). La nacionalidad granadina se 
definió, entonces, desde una perspectiva política y territorial, esto es, se asoció a la creencia de que un territorio compacto, unificado y bien definido, cuya propiedad podía autenticarse ante los propios y los extraños, así como una organización política cohesionada por principios republicanos, podían dar forma a una nacionalidad también compacta, robusta y unificada. De este ideal de nación, parece tratar Bolívar (1819d) cuando escribe:

Para sacar de este caos nuestra naciente República, todas nuestras facultades morales no serán bastantes, si no fundimos la masa del pueblo en un todo; la composición del Gobierno en un todo; la legislación en un todo; y el espíritu nacional en un todo. Unidad, unidad, unidad, debe ser nuestra divisa. La sangre de nuestros ciudadanos es diferente, mezclémosla para unirla; nuestra Constitución ha dividido poderes, enlacémoslos para unirlos; nuestras leyes son funestas reliquias de todos los despotismos antiguos y modernos, que este edificio monstruoso se derribe [y caiga]. Si queremos consultar monumentos y modelos de legislación, la Gran Bretaña, la Francia, la América Septentrional los ofrecen admirables.

Estas ideas ponen de relieve la diferencia existente entre una comprensión etnonacional de la nacionalidad y la soberanía, y una concepción procedimental. Se trata de la diferencia existente entre una comprensión del principio de nacionalidad que justifica el derecho a la autodeterminación política, apelando a una idea de pueblo soberano, concebido como una totalidad étnicamente uniforme y como un fatum histórico preconstitucional; y una idea procedimental de la soberanía y la nacionalidad que concibe al pueblo como la asociación de individuos libres e iguales que participan y se insertan en la comunidad política.

En este aspecto, Bolívar fue enfático al señalar que, ante la imposibilidad de saber con precisión a qué familia humana pertenecíamos los americanos, era necesario formular un principio de pertenencia política e impersonal que trascendiera los lazos de afinidad natural y biológica como la sangre, la lengua y la raza. Este ideario se fundamentaba en los principios de la soberanía del pueblo, proscripción de la esclavitud, división de poderes, libertad civil, igualdad política, gobierno representativo, fomento del amor patriótico, y abolición de 
la monarquía y sus privilegios. En este sentido, su doctrina se sitúa, a través de Maquiavelo (1987), Montesquieu (1984) y Rousseau (1993 y 2016), en el horizonte de la modernidad política, para postular la libertad civil y la igualdad como características distintivas de la nación. El llamado de atención de Bolívar a los legisladores venezolanos, es preciso y contundente:

Nacidos todos del seno de la misma madre, nuestros padres diferentes en origen y en sangre, son extranjeros, y todos difieren visiblemente en la epidermis [...]. Los ciudadanos de Venezuela gozan todos por la Constitución, intérprete de la naturaleza, de una perfecta igualdad política. Cuando esta igualdad no hubiese sido un dogma en Atenas, en Francia y en América, deberíamos nosotros consagrarlo para corregir la diferencia que aparentemente existe (Bolívar, 1819c).

A la hora de equilibrar la búsqueda de la unidad y pacificación interna con la necesidad de particularizarse respecto del viejo mundo, Bolívar se enfrentó con el hecho evidente de una población con caracteres desemejantes, de bajo nivel de instrucción y atada a principios hispanocatólicos. Por tal razón, no postuló que los individuos tuvieran que ser iguales cultural y racialmente, sino que participaran de un vínculo de solidaridad necesario para llevar a cabo acciones en conjunto. En ese sentido, el affectus patrius -o amor patrióticofue entendido como el resorte principal del gobierno republicano, y el espíritu nacional, como la expresión de la voluntad general del pueblo soberano.

Dos asuntos inquietaban al Libertador. Por un lado, cómo justificar la construcción de una república soberana e independiente en nombre de un pueblo que no existía, es decir, cómo refundar a un pueblo como el venezolano que, al decir de Bolívar, había sido corrompido, degradado y esclavizado durante tres siglos de opresión y dominación hispánica. Y, por otro lado, cuál debía ser el modelo político adecuado para esa nueva república. Sobre el primer asunto, Bolívar afirmó que, entre el pueblo abstracto de la Francia revolucionaria y el pueblo virtuoso de la América septentrional, se hallaban los pueblos de la América hispánica, los cuales habían sido "colocados en un grado inferior al de la servidumbre", pues no solo se les había arrebatado la libertad, sino también "la tiranía activa y 
doméstica". En tal sentido, la tarea era urgente y delicada, pues se debía transformar, en muy poco tiempo, "a hombres pervertidos" en verdaderos patriotas (Bolívar, 1819b).

Respecto al segundo asunto, Bolívar acudió a la tesis planteada por Rousseau (1993) en El contrato social, según la cual lo mismo que un "arquitecto, antes de levantar un edificio, observa y sondea el terreno para ver si puede soportar el peso de aquél, así el sabio legislador no comienza por redactar leyes buenas en sí mismas, sino que antes examina si el pueblo es apto para recibirlas" (p. 439). El propósito de ofrecer una ojeada sobre el pasado de Venezuela era, justamente, analizar cuál debía ser la Constitución adecuada a las necesidades de un pueblo que quería regenerarse. Para Bolívar, un pueblo o cuerpo político estaba bien conformado si había correspondencia entre sus instituciones y la extensión de su territorio, su clima, su geografía y el genio, el carácter, los gustos y las costumbres del pueblo. Esto es, si hay correspondencia entre sus leyes y aquella fisonomía que lo hacen ser él y no otro. Buscando trazar una diferencia geográfica con los nacidos en la América del Norte, Bolívar (1819b) afirma:

Pero sea lo que fuere, de este Gobierno con respecto a la Nación Americana debo decir, que ni remotamente ha entrado en mi idea asimilar la situación y naturaleza de dos Estados tan distintos como el Inglés Americano y el Americano Español. ¿No sería muy difícil aplicar a España el código de Libertad política, civil y religiosa de Inglaterra? Pues aún es más difícil adaptar en Venezuela las leyes del Norte de América. ¿No dice el Espíritu de las Leyes que estas deben ser propias para el Pueblo que se hacen? ¿Que es de una gran casualidad que las de una Nación puedan convenir a otra? ¿Que las leyes deben ser relativas a lo físico del país, al clima, a la calidad del terreno, a su situación, a su extensión, al género de vida de los Pueblos?

En este punto, Bolívar suscribió las premisas de Maquiavelo, Montesquieu y Rousseau según las cuales el resorte principal de las instituciones republicanas, y lo que les permite actuar, es la virtud de sus ciudadanos. El presupuesto republicano es claro. A través de la recuperación de las instituciones nacionales, las prácticas y los ritos públicos se pueden crear hábitos queridos y afectos indestructibles (Bolívar, 1950b, p. 837). Estas y aquellos no solo singularizan a un pueblo y lo distinguen de otros, sino que unen afectivamente a los 
ciudadanos a la patria y a los compatriotas entre sí (Rousseau, 2016, pp. 70-72). ${ }^{4}$ Retomando la máxima de Maquiavelo, según la cual "un pueblo corrompido que ha alcanzado la libertad, muy difícilmente se mantendrá libre" (p. 81), ${ }^{5}$ Bolívar concibió la educación como la antorcha que le enseña al hombre vicioso el camino seguro de las virtudes públicas. Este proceso demanda un enorme esfuerzo en el cultivo de las virtudes patrióticas. Al respecto, el Libertador señala que:

La educación popular debe ser el cuidado primogénito del amor paternal del Congreso. Moral y luces son los polos de una República, moral y luces son nuestras primeras necesidades. Tomemos de Atenas su Areópago, y los guardianes de las costumbres y las Leyes; tomemos de Roma sus censores y sus tribunales domésticos, y haciendo una Santa alianza de estas instituciones morales, renovemos en el Mundo la idea de un Pueblo que no se contenta con ser libre y fuerte, sino que quiere ser virtuoso (Bolívar, 1819d).

Y, en el discurso La instrucción pública pronunciado en 1825, enfatiza en el valor político de la educación y la ilustración de los ciudadanos, en los siguientes términos:

El Gobierno forma la moral de los pueblos, los encamina a la grandeza, a la prosperidad, y el poder. ¿Por qué? Porque teniendo a su cargo los elementos de la sociedad; establece la educación pública y la dirige. La Nación, será sabia, virtuosa y guerrera, si los

4 Bolívar (1819a) adhirió a las premisas del autor ginebrino, señalando que la libertad "es un alimento suculento, pero de difícil digestión. Nuestros débiles conciudadanos tendrán que robustecer su espíritu mucho antes que logren digerir el saludable nutritivo de la libertad". En este fragmento, Bolívar remite, casi textualmente, a las tesis expuestas por Rousseau en "Consideraciones sobre el gobierno de Polonia y su proyecto de reforma" cuando afirma que: "la libertad es un alimento jugoso, pero de fuerte digestión: son necesarios estómagos muy sanos para soportarlo. Me hacen reír esos pueblos envilecidos que dejándose arrastrar por agitadores osan hablar de libertad sin siquiera tener su idea y se imaginan que para ser libres basta con ser rebeldes (p. 88).

5 Los conceptos de Maquiavelo que influenciaron el pensamiento y la acción política del Libertador son: el de buenas armas, es decir, el papel de un Ejército compuesto por patriotas, no mercenarios; el de buenas leyes, esto es, de modelos de conducta social e individual que sirvan de fundamento para el gobierno; y, finalmente, el de buen ciudadano, el ideal del patriota que siempre da prioridad a los valores de la patria sobre los extranjeros o individuales. Maquiavelo y, con él, Bolívar dejaron establecido que quien pretendiera instituir o reformar un gobierno debía conservar algunos usos antiguos, y desarrollar y cultivar la virtud colectiva, de modo que se pudieran mandar ejércitos, confortar al pueblo, mantener en su estado a los hombres buenos, y avergonzar a los malos (Maquiavelo, 1987, p. 81). 
principios de su educación son sabios, virtuosos y militares [...]. El Director de una escuela, es decir el hombre generoso y amante de la Patria, que sacrificando su reposo y su libertad se consagra al penoso ejercicio de darle ciudadanos al Estado que le defiendan, le ilustren, le santifiquen, le embellezcan, y le engendren otros tan dignos como él: merece la veneración del pueblo y el aprecio del Gobierno. Él debe alentarle y concederle distinciones honrosas (Bolívar, 1950b, pp. 832-833).

Este afecto amoroso por la patria se presentó en tres dimensiones en el discurso del Libertador. En primer lugar, como un instrumento funcional para motivar y generalizar los sentimientos de pertenencia y estimación de los ciudadanos entre sí, y de cada uno de ellos con el proyecto político y legislativo iniciado en la época de la Independencia. En segundo lugar, como un principio de justicia retrospectiva hacia la obra, los esfuerzos, los sacrificios y hazañas de los héroes y mártires de la patria. Finalmente, como un modelo de amor familiar o personal que reclamaba una parcialidad especial hacia la propia patria, los padres de la patria, los hijos de la patria y los compatriotas.

\section{La nación como república}

El pensamiento de Bolívar ilustra la naturaleza plural y mixta del lenguaje republicano que circuló en el momento de la Independencia. Paola Rudan (2007) y Jaime Urueña Cervera (2007) sostienen, en polémica con la tradición que sustenta la leyenda negra del Libertador, que este recorre "la senda de occidente", incorporando a sus propuestas políticas tesis republicanas provenientes de autores diversos. Estos dos estudiosos indican que, en sus planteamientos sobre el modelo constitucional que consideraba adecuado a las condiciones de Venezuela, Colombia y Bolivia, Bolívar recuperó la experiencia de las repúblicas griegas, la república romana, las repúblicas italianas, la Francia revolucionaria y los Estados Unidos (Rudan, 2007, pp. 118-127; Urueña, 2007, pp. 17-45). Además, agregan que la doble imagen que Bolívar trasmite de sí mismo, como dictador y legislador, constituye una figura básica de toda la tradición republicana.

Como legislador, Bolívar afirmó los principios de igualdad, libertad y democracia representativa, además, señaló que eran las situaciones concretas las que mostraban que no todas las pretensiones tenían igual fuerza, y que los valores políticos debían ser asumidos 
desde un equilibrio precario. Declaraba que los valores políticos de la libertad y la autoridad no podían tener el mismo peso en el ambiente de conmoción, disgregación interna y corrupción que vivía el pueblo venezolano. Por ello, la independencia de las repúblicas americanas requería de un poder fuerte capaz de hacer valer la ficción de la unidad soberana. En este punto, compartió las tesis republicanas sobre la necesidad de trazar una frontera intercambiable y móvil entre el deseo de todos los hombres de estar libres de toda coerción y la necesidad de la autoridad para garantizar la supervivencia de la sociedad (Urueña, 2007, p. 97). Bolívar hizo de la patria, la nación y la república conceptos equivalentes. Entendió la nación como sinónimo de patria y emparentó la patria con la libertad como autodeterminación. Y, consecuentemente, el republicanismo fue adoptado como teoría ideal del poder, principio de legitimidad y matriz constitucional de sus proyectos de Estado.

Que la nación aparezca de mano de la república quiere decir varias cosas. Significa que la nación se imaginó y se pensó, primariamente, como una nación querida por los ciudadanos, es decir, como una nación fundada por principios de lealtad cívico-política, mediada por el estatus de ciudadanía y conformada, hipotéticamente, por individuos libres e iguales, despojados de sus particularidades étnicas. Quiere decir, también, que las ideas emancipadoras fueron concebidas como un principio de autodeterminación política, que entendía a la nación como la reunión libre y voluntaria de individuos y pueblos que quieren constituir un Estado independiente. Finalmente, quiere indicar que los "pioneros criollos" establecieron una relación de complementariedad entre el principio de autodeterminación nacional y el derecho del individuo al libre albedrío.

6 Se usa la expresión de "pioneros criollos" acuñada por Benedict Anderson (1993) para resaltar el carácter peculiar e inédito del proceso de construcción nacional en la América hispánica. Sobre el adjetivo de "pioneros criollos", Anderson ofrece dos explicaciones: por un lado, señala que las comunidades criollas concibieron la idea de su nacionalidad mucho antes que la mayor parte de Europa, y, por el otro, afirma que los esquemas explicativos utilizados para estudiar el surgimiento de las naciones europeas no pueden aplicarse al caso hispanoamericano, ya que el nacionalismo americano rompe la conexión existente entre las lenguas nacionales impresas y el Estado nacional, y presenta un movimiento nacionalista que no tiene connotaciones populistas (pp. 77-101). 
Desde la perspectiva de Bolívar, la dicotomía no era, entonces, entre la libertad y la autoridad, entre la libertad de los antiguos y la de los modernos, sino entre los valores absolutos del poder y la libertad ilimitados. Para él, estos dos extremos debían ser corregidos si se quería dar lugar a un gobierno republicano sustentado en la libertad social y el poder legítimo. Buscando demostrar las bondades del equilibrio entre los poderes, y justificando la propuesta del "poder moral", el Libertador afirmó:

Meditando sobre el modo efectivo de regenerar el carácter y las costumbres que la tiranía y la guerra nos han dado, me he sentido la audacia de inventar un Poder Moral, sacado del fondo de la obscura antigüedad, y de aquellas olvidadas leyes que mantuvieron, algún tiempo, la virtud entre los Griegos y los Romanos. Bien puede ser tenido por un cándido delirio más no es imposible, y yo me lisonjeo que no desdeñaréis enteramente un pensamiento que, mejorado por la experiencia y las luces, puede llegar a ser muy eficaz (Bolívar, 1819a).

Y en otro lugar del Discurso afirma que:

Todos los pueblos del mundo han pretendido la libertad; los unos por las armas, los otros por las leyes, pasando alternativamente de la anarquía al despotismo o del despotismo a la anarquía [...]. No aspiremos a lo imposible, no sea que, por elevarnos sobre la región de la Libertad, descendamos a la región de la tiranía. De la Libertad absoluta se desciende siempre al poder absoluto, y el medio entre estos dos términos es la Suprema Libertad Social [...]. Para formar un gobierno estable se requiere la base de un espíritu nacional que contenga una inclinación uniforme hacia dos puntos capitales: moderar la voluntad general y limitar la autoridad (Bolívar, 1819d).

Tomar como punto de partida el sustrato republicano, subyacente a la idea de nación postulada por el Libertador obliga a tener presente que el republicanismo de la época, más que un sistema

7 El proyecto de un "poder moral" orienta el propósito del Libertador de institucionalizar la virtud republicana y conservar los valores patrióticos. Este poder estaría configurado a la manera de una Asamblea, el Areópago, cuya función principal sería el cuidado del Congreso, la moral y las luces (Bolívar, 1819d). Un análisis completo sobre este proyecto en la obra legislativa, educativa y constitucional de Bolívar puede verse en Rudan (2007, pp. 216-246). 
de pensamiento compacto y homogéneo, fue un lenguaje político plurívoco y un concepto de movimiento y acción política. Tras la ruptura del vínculo colonial, la república se impuso como antítesis de la monarquía, en especial de la española. José Antonio Aguilar Rivera (2002) la denomina "república epidérmica", para resaltar que el entendimiento que las élites patrióticas tenían de ella era eminentemente formal e institucional (p. 73).

Más allá de si se trató o no de una república "epidérmica" o "densa", el republicanismo fue asumido como una tradición plural, más que como una ideología uniforme. Como concepto de movimiento e ideología plural, pudo albergar, sin incurrir en contradicciones, elementos liberales y principios católicos, así como características modernas y principios de la tradición republicana clásica.

Las afirmaciones anteriores se inscriben en el contexto de los análisis que han desplazado la atención del liberalismo al republicanismo, como matriz explicativa del nacimiento de las naciones modernas en Hispanoamérica. ${ }^{8}$ Rafael Rojas (2002) y José Antonio Aguilar (2002) han señalado, por ejemplo, que cuando los hispanoamericanos enfrentaron la tarea de diseñar las instituciones de sus nuevas naciones, el modelo de la república liberal ya existía, de modo que la encrucijada entre la república clásica y la moderna había quedado atrás. Estos autores también han señalado que lo republicano, más que indicar la adopción de una forma de gobierno antimonárquica, alude a la tradición cívica y patriótica que se remonta al mundo clásico (Rojas, 2002, p. 388; Aguilar, pp. 73-83).

En efecto, la república como forma de gobierno representativo, electivo y popular, estuvo en la mente del Libertador cuando se planteó la tarea de transformar, en muy poco tiempo, una sociedad del Antiguo Régimen en un orden republicano moderno. Bolívar tomó como modelo el entramado político de la república moderna y, sobre todo, del republicanismo francés y norteamericano: gobiernos

8 Esta ha sido, en parte, la intención de los trabajos de José Antonio Aguilar y Rafael Rojas. La motivación surge del impulso que la historiografía de la denominada Escuela de Cambridge ha dado al rescate de la tradición republicana como una corriente intelectual distinta y opuesta al liberalismo. El referente fundamental de estos trabajos está en las obras de J. Pocock (2014) y Quentin Skinner (1985), y su intención es descentrar al liberalismo como ideología hegemónica dominante y explicativa de todos los procesos políticos hispanoamericanos del siglo XIX. 
electivos, separación de poderes, constituciones escritas, derechos individuales e igualdad jurídica. De igual modo, usó como recursos permanentes de exempla virtutis a Roma y Esparta, y adoptó diversas fuentes intelectuales: el lenguaje jurídico del iusnaturalismo ibérico de Francisco de Victoria (1998); y el Derecho Natural y de Gentes de Vattel (1822); y el ideario revolucionario de los padres fundadores de Norteamérica. También consideró que, para sus diseños constitucionales, Gran Bretaña era el modelo seguir.

No se trató, sin embargo, de una simple mímesis de las naciones antiguas y modernas. La autocomprensión de Bolívar y de la dirigencia política de la época era la de ser partícipes y miembros activos de un gran movimiento universal que estaba sacudiéndose de las estructuras tradicionales del Antiguo Régimen, legislando contra la tradición y labrando su propio destino como naciones soberanas. En otras palabras, la autopercepción que tenía la dirigencia patriótica era la de estar contribuyendo, desde esta orilla del Atlántico, al avance de las fuerzas del progreso y la civilización. Bolívar lo presentó claramente cuando señaló que, sentado en "el trono de la libertad, empuñando el cetro de la justicia [y coronado] por la gloria”, el Nuevo Mundo podía mostrarle su majestad y superioridad al Mundo Antiguo (Bolívar, 1819a).

La ambigüedad que puede presentarse en el texto de Bolívar es el resultado del uso de fuentes doctrinales heterogéneas y modelos nacionales diversos, es decir, de un sincretismo político en el que se mezclaron temas, ideas y preocupaciones que podrían verse como incompatibles e irreconciliables. En el republicanismo del libertador confluyen la dimensión jurídico-formal del gobierno representativo, con las tesis del autogobierno; del ejercicio de las libertades antiguas, de la virtud cívica y de la necesidad de un gobierno fuerte, centralizado y sólido. Su propuesta política y constitucional resultó ser, en la práctica, más que una ideología uniforme, la síntesis de lo formal y lo sustantivo, lo antiguo y lo moderno. Y por ello pudo albergar, sin incurrir en contradicciones, elementos liberales con principios católicos, orgánicos y comunitarios; características modernas con postulados de la tradición republicana clásica; y aspiraciones centralistas con postulados democráticos. 
En la retórica de Bolívar, se conjuga la relación afectiva y moral con la tierra natal, así como con el ideal de la comunidad legal y política a la que se le deben lealtad y sacrificio. Este ideal suscribe la perspectiva moderna del republicanismo, según la cual el amor a la patria, en un sentido más noble, exige que ella "se entienda en el sentido de pueblo, como, por otro lado, casa se entiende en sentido de familia. Sin embargo, no es el pueblo como un conjunto o una clase de personas, sino que es la unión la que hace de ese conjunto de personas una nación, un pueblo, la ley [y] la constitución" (Koselleck, 2012, p. 147). El espíritu de ese ideal republicano, preocupado por la forma como un pueblo se constituye en pueblo, está presente, de manera explícita, en la respuesta que Bolívar (1819b) da a la pregunta sobre cuál es el gobierno que conviene a Venezuela:

Meditad bien vuestra elección, legisladores. No olvidéis que vas a echar los fundamentos de un Pueblo naciente que podrá elevarse a la grandeza que la naturaleza le ha señalado, si vosotros proporcionáis su base al eminente rango que le espera [...]. Un gobierno republicano ha sido, es y debe ser el de Venezuela; sus bases deben ser la soberanía del pueblo, la división de poderes, la libertad civil, la proscripción de la esclavitud, la abolición de la Monarquía y de los privilegios.

\section{La gran nación}

La reunión de la Nueva Granada y Venezuela en un grande Estado, ha sido el voto uniforme de los pueblos y gobiernos de estas Repúblicas [...]. Al contemplar la reunión de esta inmensa comarca, mi alma se remonta a la eminencia que exige la perspectiva colosal, que ofrece un cuadro tan asombroso. Volando por entre las próximas edades, mi imaginación se fija en los siglos futuros, y observando desde allá, con admiración y pasmo, la prosperidad, el esplendor, la vida que ha recibido esta vasta región, me siento arrebatado y me parece que ya la veo en el corazón del universo, extendiéndose sobre sus dilatadas costas entre esos océanos que la naturaleza había separado [...]. Ya la veo sentada sobre el trono de la libertad, empuñando el cetro de la justicia, coronada por la gloria, mostrando al Mundo Antiguo la majestad del Mundo Moderno (Bolívar, 1819a). 
Con este expresivo y emotivo fragmento concluye el Discurso de Angostura. En él, Simón Bolívar evoca el ideal de una gran nación que sería el resultado de la unión entre la Nueva Granada y Venezuela, tal como lo había presagiado, en 1815, en la "Contestación de un Americano Meridional a un Caballero de la Isla" -Carta de Jamaica- (Bolívar, 1950a). Esta gran nación se llamaría Colombia, como tributo de justicia y gratitud a Cristóbal Colón; podría tener como capital a Maracaibo o a otra ciudad con el nombre de Bartolomé de las Casas. Su gobierno podría imitar al inglés, retomando de él "todo lo que tiene de republicano y su constitución participaría de las mejores formas y de ninguno de sus vicios" (Bolívar, 1950, p. 171). La creación de este gran Estado hacía realidad la intención de Bolívar de ver a América como una sola patria. Tal como lo afirma Gerhard Masur (1987), el Congreso de Angostura significó, para el Libertador, una triple victoria: reafirmó su posición personal reteniendo el poder -aunque fuera bajo el manto de la ley-, silenció a sus críticos, y presentó ante el mundo una nueva nación-república en calidad de Estado independiente (p. 332).

Habría que esperar los triunfos militares en los campos de Boyacá, Carabobo y Pichincha, y la posterior promulgación de la Constitución de la República de Colombia, en 1821, para que se diera una ruptura definitiva con la metrópoli y se declarara el nacimiento de la nación colombiana como "irrevocablemente libre e independiente de la Monarquía española y de cualquier otra potencia o dominación extranjera" (Pombo y Guerra, 1986, p. 69). En aquella Constitución se delimitaron las fronteras del territorio colombiano, se declaró que la soberanía residía, esencialmente, en la nación, y se ratificó que el gobierno de Colombia era popular, representativo y dividido. Al decir de José María Samper (1974), con excepción del carácter fuertemente centralista, visto como una necesidad imperiosa ante los excesos provocados por el federalismo, la anarquía y la disputa por las soberanías entre las provincias, esa obra constitucional reunía los principios generales e indispensables de una organización republicana, y establecía las condiciones fundamentales de una nación moderna (p. 157).

De las consideraciones presentadas aquí se pueden extraer algunas ideas generales que contribuyen a delimitar la especificidad del 
vínculo que supone el ideal republicano de nación postulado por el Libertador. La primera señala que Bolívar optó por un ideal de nación que mantenía la primacía de las dimensiones política y territorial sobre las identidades etnoculturales y etnoterritoriales. Estas ideas prevalecieron a lo largo del siglo XIX y le dieron forma a un ideal de nacionalidad compleja que hizo del estatus de ciudadanía el supuesto igualitario que prometía superar las tensiones resultantes de la desigualdad natural y de la heterogeneidad jerárquica heredada del Antiguo Régimen.

La segunda afirma que, para Bolívar, nación y patria son términos equivalentes. La patria reúne las dimensiones existenciales; la nación las hace conscientes. Aquí, se vislumbran dos atributos que son determinantes en la nacionalidad moderna: la dimensión sentimental, que asume a la nación como una comunidad sentida y define los diversos modos en que los conciudadanos o connacionales son como uno mismo; y la dimensión política, que señala que no es el nombre u otras características objetivas lo que opone la nación a otras formas de agrupación humana, sino la naturaleza del vínculo que une a los hombres. La nación como república está integrada en torno a un poder central y está articulada por el estatus de la ciudadanía.

La tercera idea señala que la existencia de una república central, compacta y unificada, requiere de la educación civil y del fomento de las virtudes patrióticas. La nación es, en este aspecto, un espacio de legitimación que se opone, en tanto fuente del poder, al gobierno absoluto, al poder real y al derecho divino. Bolívar es, sin duda, defensor de un modelo republicano que fundamenta la legitimidad en la regeneración del individuo y su transformación en ciudadano. Esta es, como se sabe, la premisa legitimadora de gran parte de la tradición republicana.

La cuarta idea remite a los sentidos interior y exterior del concepto de nación como república. En el primero de ellos, se alude a un sentimiento o un pathos específico, cercano a la virtud del patriotismo como la cualidad central de los nacionales y naturalizados en el Estado. Por su parte, en su sentido exterior, la nación está relacionada con la clara distinción entre un adentro y un afuera. Por los triunfos verificados en la guerra de emancipación y con la España humillada, esta nueva nación podía afirmarse como sujeto soberano frente otras unidades políticas $\mathbf{C}$ 


\section{Referencias}

Aguilar Rivera, J. A. (2002). Dos conceptos de república. En: J. A. Aguilar y R. Rojas (coords.), El republicanismo en Hispanoamérica. Ensayos de historia intelectual y política (pp. 57-85). México: FCE.

Bolívar, S. (1950a). "Contestación de un Americano Meridional a un Caballero de la Isla" -Carta de Jamaica-[1815]. En: Obras Completas (Tomo I, pp. 159-175). La Habana: Editorial Lex.

Bolívar, S. (1950b). "La instrucción pública” [1825]. En: Obras Completas (Tomo III, pp. 832 837). La Habana: Editorial Lex.

Bolívar, S. (20 de febrero de 1819a). Discurso pronunciado por el General Bolívar al Congreso general de Venezuela en el acto de su instalación. Correo del Orinoco, 19.

Bolívar, S. (27 de febrero de 1819b). Continuación del Discurso del General Bolívar al Congreso el día de su instalación. Correo del Orinoco, 20.

Bolívar, S. (6 de marzo de 1819c). Continuación del Discurso del General Bolívar al Congreso el día de su instalación. Correo del Orinoco, 21.

Bolívar, S. (13 de marzo de 1819d). Conclusión del discurso del General Bolívar al Congreso el día de su Instalación. Correo del Orinoco, 22.

Chiaramonte, J. C. (2008). Conceptos y lenguajes políticos en el mundo iberoamericano, 1750-1850. Revista de Estudios Políticos, 140, 11-31.

Guerra, F.X. (1992). Modernidad e independencias. Ensayos sobre las revoluciones hispánicas. México: FCE.

Guerra, F.-X. (2012). Figuras de la modernidad. Hispanoamérica siglos xIX-xx. Bogotá, Taurus/ Universidad Externado de Colombia.

Jaramillo Uribe, J. (1994). La personalidad histórica de Colombia y otros ensayos. Bogotá: El Áncora Editores.

König, H. J. (1994). En el camino hacia la nación. Nacionalismo en el proceso de formación del Estado y de la nación de la Nueva Granada, 1750-1856. Bogotá, Banco de la República,

Koselleck, R. (2012). Historias de conceptos. Estudios sobre semántica y pragmática del lenguaje político y social. Madrid: Trotta.

Maquiavelo, N. (1987). Discursos sobre la primera década de Tito Livio (Libro I). Madrid: Alianza.

Masur, G. (1987). Simón Bolívar. Caracas: Grijalbo.

Montesquieu, C. L. de Secondat. (1984). El espiritu de las leyes. Madrid, Sarpe. 
Núñez, Rafael. (1986). "La federación” [1855]. En: Escritos políticos. Bogotá, El Áncora Editores.

Pocock, J. G. A. (2014). El momento Maquiavélico. El pensamiento político florentino y la tradición republicana atlántica. Madrid: Tecnos.

Pombo, M. A. y Guerra J. J. (1986). Constituciones de Colombia (Tomo III). Bogotá: Banco Popular.

Quijano Otero, José María. (1881). Los límites de la república de los Estados Unidos de Colombia. Bases generales: los tratados hispanolusitanos -el uti possidetis de 1810-. Sevilla, Francisco Álvarez Editores.

Rojas, R. (2002). La frustración del primer republicanismo mexicano. En: J. A. Aguilar y R. Rojas (coords.), El republicanismo en Hispanoamérica. Ensayos de historia intelectual y política (pp. 388-423). México: FCE.

Rousseau, J. J. (1993). El contrato Social. Barcelona: Altaya.

Rousseau, J. J. (2016). "Consideraciones sobre el gobierno de Polonia y su proyecto de reforma" En: Escritos constitucionales. Madrid: Tecnos.

Rudan, P. (2007). Por la senda de occidente. Republicanismo y constitución en el pensamiento político de Bolivar. Madrid: Biblioteca Nueva.

Samper, J. M. (1879). Galería nacional de hombres ilustres o notables. Colección de bocetos biográficos. Bogotá: Imprenta de Zalamea.

Samper, J. M. (1974). Derecho público interno de Colombia. Bogotá: Banco Popular.

Skinner, Q. (1985). Los fundamentos del pensamiento político moderno. México: FCE.

Urueña Cervera, J. (2007). Bolivar republicano. Fundamentos ideológicos e históricos de su pensamiento. Bogotá: Aurora.

Vattel, Emerich de. (1822). Derecho de gentes o principios de la ley natural aplicados a la conducta y los negocios de las naciones. París, Imprenta de Everat en Casa de Leconte.

Victoria, Francisco de. (1998). Sobre el poder civil, sobre los indios y sobre el derecho de la guerra. Madrid: Tecnos. 